\title{
Assessing the Management of Excessive Daytime Sleepiness by Napping Benefits
}

\author{
Eric Murillo-Rodríguez ${ }^{1,2}$ (1) $\cdot$ Tetsuya Yamamoto ${ }^{2,3} \cdot$ Diogo Monteiro $^{2,4,5} \cdot$ Henning Budde $^{2,6} \cdot$ Nuno Barbosa Rocha ${ }^{2,7}$.

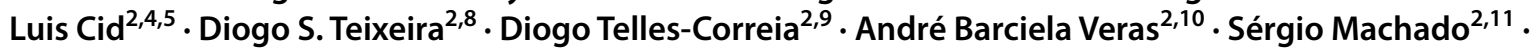 \\ Claudio Imperatori ${ }^{2,12} \cdot$ Pablo Torterolo ${ }^{2,13}$
}

Received: 9 March 2020 / Revised: 20 April 2020 / Accepted: 28 May 2020 / Published online: 8 June 2020

(c) Springer Nature Singapore Pte Ltd. 2020

\begin{abstract}
Purpose Demanding lifestyle characterized by extended working hours, shift work schedules as well as excessive use of mobile gadgets leads to the disruption of the circadian and homeostatic factors affecting the sleep quality of individuals. As consequence, subjects complain of suffering several sleep disorders some of them characterized by inducing excessive daytime sleepiness (EDS). Currently, the therapeutic approaches for managing EDS include medication, promotion of sleep hygiene, cognitive and behavioral therapy or using of continuous positive airway pressure machine. In this review, we propose the posology of the personalized sleep medicine by the prescription of naps for treating EDS.

Methods This review included the online search in PubMed and manual review of articles (basic and clinical trials) of a range of personalized medicine potentially associated to factors of dosage in areas such as nutrition, sports and sleep. Articles in English were identified and subsequently analyzed for consideration for this review.

Results Current evidence has demonstrated that naps exert positive outcomes for individuals complaining with EDS. The dosage of naps might follow similar procedures as reported for personalized interventions in diets or exercise programs (by taking the right dose, at the proper time, with a recommended frequency) which have demonstrated successfully results.

Conclusions The management of EDS may include the personalized sleep medicine considering the prescription of dosage of naps.
\end{abstract}

Keywords Diets $\cdot$ Dose $\cdot$ Exercise $\cdot$ Food

Eric Murillo-Rodríguez

eric.murillo@anahuac.mx

1 Laboratorio de Neurociencias Moleculares e Integrativas, Escuela de Medicina, División Ciencias de la Salud,

Universidad Anáhuac Mayab, Km. 15.5 Carretera

Mérida-Progreso, Int. Km. 2 Carretera a Chablekal,

C.P. 97308 Mérida, Yucatán, Mexico

2 Intercontinental Neuroscience Research Group, Mérida, Yucatán, Mexico

3 Graduate School of Technology, Industrial and Social Sciences, Tokushima University, Tokushima, Japan

4 Research Center in Sport, Health and Human Development-CIDESD, Vila Real, Portugal

5 Sport Science School of Rio Maior-Polytechnic Institute of Santarém, Rio Maior, Portugal

6 Faculty of Human Sciences, Medical School of Hamburg, Hamburg, Germany
7 School of Health, Polytechnic Institute of Porto, Porto, Portugal

8 Interdisciplinary Center for the Study of Human Performance (CIPER), Universidade Lusófona de Humanidades e Tecnologias, Lisbon, Portugal

9 Faculty of Medicine, University of Lisbon, Lisbon, Portugal

10 Medical School at State University of Mato Grosso do Sul, Campo Grande, Mato Grosso do Sul, Brazil

11 Laboratory of Physical Activity Neuroscience, Physical Activity Sciences Postgraduate Program Salgado de Oliveira University, Niterói, Brazil

12 Cognitive and Clinical Psychology Laboratory, Department of Human Science, European University of Rome, Rome, Italy

13 Laboratorio de Neurobiología del Sueño, Departamento de Fisiología, Facultad de Medicina, Universidad de la República, Montevideo, Uruguay 


\section{Introduction}

Prolonged working hours, shifting work schedules and excessive use of mobile gadgets at night are current features of modern lifestyle leading to induce sleep disturbances [1-4]. The field of sleep disorders comprises insomnia, sleep-related breathing disorders, central disorders of hypersomnolence, circadian rhythm sleep-wake disorders, parasomnias, sleep-related movement disorders and other sleep disorders. Most of the sleep disturbances are linked to excessive daytime sleepiness (EDS), which is the tendency to fall asleep during alertness. It is worthy to highlight that this symptom is a common complaint in general population [5, 6]. Moreover, insufficient sleep has been classified as a "public health problem" since significant proportion of population sleep less hours than the recommended rising economical and health consequences [7, 8]. Although general guidelines for managing EDS have been discussed, these interventions need to be tailored to the individual patient. Therefore, the precision medicine including the timing for the appropriate quantity of sleep provided by naps may be considered for managing EDS. The present narrative review discusses the likely use of naps with a metric measurement of its use in the control of EDS.

\section{Methods}

Identified eligible original articles by searching in PubMed, included reports containing information about sleep stages and sleep architecture, sleep disorders, circadian and homeostatic factors, diets, exercise dosage, precision medicine and naps were included in the analysis. Articles were searched in the computerized databases up to July 2015, without limits of language. Next, we screened the titles and abstracts of the identified studies, and articles were selected if they contained data regarding the searched terms. The inclusion criteria were as follows: (1) Studies including sleep stages and sleep architecture, sleep disorders, circadian and homeostatic factors, naps; (2) Reports in which personalized medicine was used in diets and exercise. The exclusion criteria included non-english publications, comments, editorials, and case reports. The information used for the review was collected from each selected publication.

\section{Results}

\subsection{Sleep Stages and Sleep Architecture}

The sleep-wake cycle has been characterized in chordate (mammals, birds and Squamata), Arthropoda (flies, bees, scorpions) cnidarian (jellyfish) and nematodes species (C. elegans [9-11]). Based in electroencephalographic traces, three states of vigilance have been identified in most of the studied animals, including mammals (Fig. 1): wakefulness (W), slow wave sleep (SWS) and rapid eye movement sleep (REMS). As a consensus, W is characterized by low voltage $(10-30 \mu \mathrm{V})$, and fast $(16-25 \mathrm{~Hz})$ cortical electroencephalographic (EEG) and electromyographic (EMG) activity. The transition from $\mathrm{W}$ to SWS displays the appearance of slower frequencies and higher voltage activities observed in the EEG. In regards SWS, 3 stages have been described in humans: stage 1 is present approximately $5 \mathrm{~min}$ from the transition from $\mathrm{W}$ to SWS and includes rolling eye movements and low voltage and mixed-frequency EEG activity and decreased EMG signal. The stage 2 is characterized by bursts of sleep spindles (12-14 Hz sinusoidal waves), and highvoltage biphasic waves named "K complexes". The stage
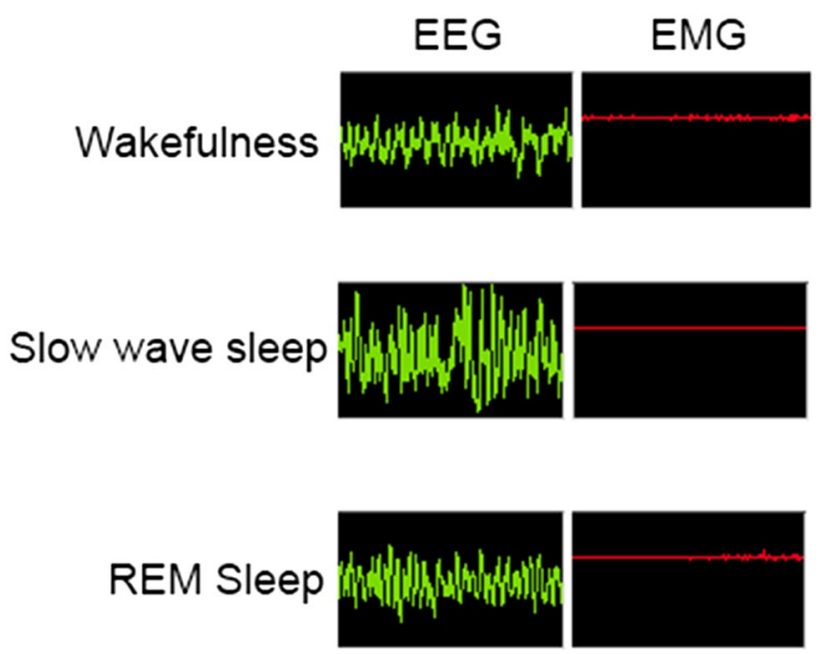

Fig. 1 The polysomnographic traces of the sleep-wake cycle. In mammals, the sleep-wake cycle is characterized in 3 stages: Wakefulness, slow wave sleep and rapid eye movement (REM) sleep. Waking consists in EEG patterns of rapid (alpha) activity $(8-13 \mathrm{~Hz})$ while the EMG signal shows higher activity. The slow wave sleep shows in the EEG spindle activity accompanied by low voltage, $\mathrm{K}$ complexes and waves over $100 \mu \mathrm{V}$ of amplitude and less than $2 \mathrm{~Hz}$ frequency while the EMG patter is reduced compared to wakefulness. Lastly, REM sleep shows in the EEG, low voltage with mixed frequencies $(2-7 \mathrm{~Hz})$ as well as irregular bursts of rapid eye movements with atonic features or muscle twitches observed in the EMG. Abbreviations: Electroencephalogram (EEG); electromyogram (EMG); rapid eye movement (REM) sleep 
3 displays high-amplitude, slow $(0.5-2 \mathrm{~Hz})$ waves named delta waves. Lastly, REMS is characterized by muscle atonia in the EMG and EEG patterns that resemble those during alertness as determined by high-frequency and low-amplitude voltage [12, 13].

The sleep-wake cycle, as another neurobiological functions, displays aberrant features classified as sleep disorders [14]. The family of sleep abnormalities encompasses insomnia, sleep-related breathing disorders, central disorders of hypersomnolence, circadian rhythm sleep-wake disorders, parasomnias, sleep-related movement disorders and other sleep disorders. They are traditionally divided into two broad categories: dyssomnias (characterized by abnormalities in the quantity or quality of sleep) and parasomnias (associated with difficulty initiating or maintaining sleep or excessive sleepiness).

\subsection{The Control of the Sleep-Wake Cycle: Circadian and Homeostatic Factors}

The sleep-wake cycle is under the orchestration of a diversity of neuroanatomical, neurochemical and genetical substrates [15-18]. Moreover, circadian and homeostatic factors also exert influence on the control of the sleep-wake cycle. In this regard, the circadian rhythms facilitate temporal patterns to the organisms for periods of time of $24 \mathrm{~h}$. The circadian component of sleep modulation is known as Process $\mathrm{C}$, which fluctuates within a cycle of $\sim 24 \mathrm{~h}$ and it is synchronized by external signals, including the light-dark period [19, 20].

Regarding the homeostatic process (Process S), diverse physiological systems, including the sleep-wake cycle, display mechanisms that detect deficits of normal states and in response exert biological adjustments. In the case of the sleep homeostasis, this process consists in the drive for sleep that increases as a result to the prolonged waking time reaching a point that sleep pressure dissipates with the sleep onset. Thus, the sleep homeostasis mechanism exerts an adjustment after periods of prolonged waking by increasing the sleeping time, known as "sleep rebound" [19-23].

The circadian and homeostatic processes suggest that the bigger the distance between Process $\mathrm{C}$ and Process $\mathrm{S}$, the higher the sleep pressure (Fig. 2). Then, the distance between both processes corresponds to the time when sleep normally is initiated. In sum, the interaction between Process $\mathrm{C}$ and Process S impacts the sleep-wake cycle and determines the importance of hourly patterns for prognosis, prevention and interventions for sleep disturbances, such as excessive sleepiness [19-24].

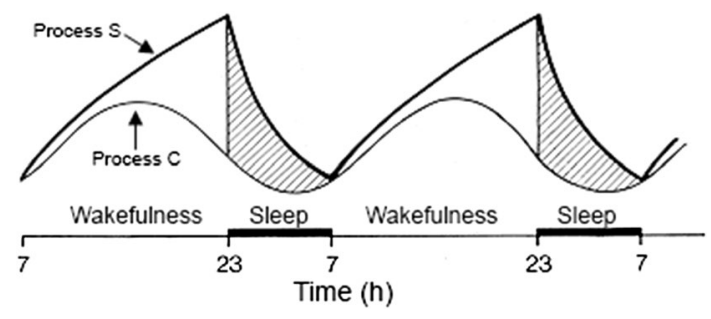

Fig. 2 The Two Processes Model of Sleep Control. The sleep-wake cycle is controlled by circadian (Process $C$ ) and homeostatic (Process $S$ ) mechanisms. In the case of the circadian component (Process $C)$, consists in a rhythm that fluctuates within a cycle of $\sim 24 \mathrm{~h}$ and this rhythmicity is under the influence of external signals such as the light-dark period. The homeostatic component (Process $S$ ) represents the drive for sleep that increases as wakefulness is maintained beyond habitual bedtime and then it dissipates with sleep, this process plays an important role during total sleep deprivation period. The homeostasis component adjusts the sleep debt by enhancing the sleeping time known as "sleep rebound" in the first opportunity to sleep. In the drawing, the black horizontal bars represent the dark period

\subsection{Dose and Dosage}

According to the National Institutes of Health in the United States of America, a dose refers to a specific amount of medication taken at certain time. The doses are expressed in conventional metric mass units, such as milligrams or milligrams per kilogram. However, depending of the type of drug, the dose might be referred in distinct units such as drops (e.g., ophthalmologic preparations). By contrast, the dosage is prescribed as a specific amount, number, and frequency of doses over a determined period [25]. In this review, we propose that EDS may be addressed by personalized sleep medicine based in the posology of timing for an appropriate dosage of sleep. The rationale on precision sleep medicine aimed to improve the patient outcomes is discussed in the context of two examples of interventions under dosage regimen.

\subsubsection{Amount of Food as a Dose}

Designed as part of nutrition intervention for managing obesity, diets are time-restricted food-intake plan within a window of time each day. Thus, the quantity or dosage of food regimen includes circadian feeding patterns distributed across the day conventionally defined as breakfast, lunch, and dinner [26]. Moreover, suggested healthy dosed balance of foods have been suggested in the Healthy Eating Plate. Hence, a subject on a time-restricted eating diet would only eat during specific hours of the day [27-29]. 


\subsubsection{Exercise Dosage}

It is worthy to highlight the differences between physical activity and exercise. For the purposes of this article, we would suggest Budde and coworkers' (2016) definitions: Physical activity is understood as any body movement produced by skeletal muscles whereas exercise is structured and planned physical activity with repetitive progress aimed to achieve physical fitness [30]. Numerous studies have examined the quantification of exercise using the concept of exercise dose [31, 32].

Dosage of food is important because for structuring diets, but why physical activity and exercise should be also dosed? We assume that all living beings of animal kingdom display in nature specie-dependent physical activity due to sedentary styles. Mankind, on the other hand, was able to set as a sedentary specie diminishing physical activity $[33,34]$. Indeed, we have left recently the nomadic lifestyle and moved to sedentary behaviors. In turn, health disorders have been linked with the sedentary lifestyle and the lack of physical activity [35-37]. To tackle some diseases linked to the lack of physical activity, current exercise dose recommends $150 \mathrm{~min}$ of moderate-intensity weekly exercise according to reports that show that $2-2.5 \mathrm{~h}$ of moderate-intensity exercise appear to be the minimum amount required to avoid no communicable diseases and premature mortalities [38, 39]. In similar fashion as diets, the dose of exercise (minimum, optimal, and maximum) has been individualized meeting specific objectives.

Current evidence has demonstrated that structured exercise dose spectrum is measurable. According to Araújo and coworkers (2017), the exercise doses could be measured by the caloric expenditure in relation to the rest value (1MET). For example, $1 \mathrm{METs}$-h/week would consist of multiplying the number of exercise hours, in each week. In line with this idea, one person that walks $(6 \mathrm{~km} / \mathrm{h})$ would display 4METs [40]. Thus, structured exercise programs are equally effective at improving training goals as well as health schedules [41-44]. In this regard, Gabriel and Zierath (2019) demonstrated that exercise as an intervention for the treatment of metabolic diseases showed positive outcomes. Remarkably, they suggested that timing of exercise for obtaining optimal results in heath might be a strategy for managing metabolic disorders since resistance exercise peaked in the afternoon and evenings (16:00-20:00 h). These findings suggested that the response to this type of exercise might be time dependent [45]. Taking together, the dose of exercise should consider the time of the day to obtain the most desirable effects [46-48].

\subsection{The Posology of Sleep}

Several measures have been proposed to counteract the EDS as consequence of sleep deprivation as result of social jetlag, consumption of stimulants, shift work, etc.[49]. Among the suggested interventions, the naps or siestas seem to be a promising approach. In this regard, multiple pieces of evidence have shown the positive outcome of napping for managing EDS [50-52]. For example, Davy and Göbel (2018) reported that taking siestas of $3 \mathrm{~h}$ and 20 min sleepiness was decreased [53]. This result is in line with previous reports showing the beneficial effects of naps for treating EDS [54-56].

\subsection{Sleep Precision Medicine and the Sun Proposal}

Precision medicine or individualized medicine is a medical process that addresses healthcare from a customized perspective [57]. In regards the impact of precision medicine in sleep disturbances, it is precisely here where personalized medicine requires the comprehension of the individual diagnostic of sleep disturbances for personalizing an efficient medical treatment [58-60]. Currently, EDS is a common sleep complaint in general population $[61,62]$ and although the availability of some prevention strategies are available, its prognosis is nevertheless often viewed as part of the intervention in a new approach. This view needs to change.

Compared to the quantification of food or dosage of exercise, the apparent limitation to establish a unit of measurement for the dosage of sleep lies in the fact that this new approach should consider for the individual sleep needs. In line with this idea, precision medicine has been aimed to maximize the quality of interventions by the individualization of the therapeutical procedures, including which intervention would be prescribed, dose, route of administration, timing of administration, etc. $[63,64]$. Thus, we propose that sleep dosage should also follow the personalized medicine guidelines. To consider a dosage of sleep by using naps will require further objective study. Therefore, we propose a standardized procedure to provide an objective measurement for the dosage of sleep. To address this point, current technological advances have allowed to develop personal

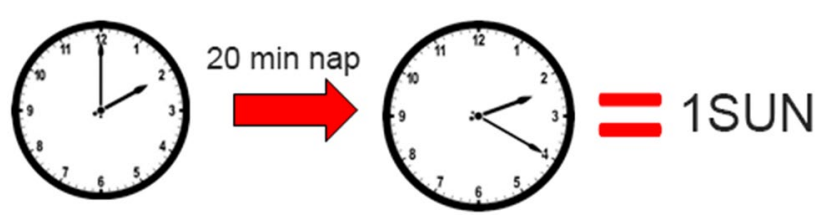

Fig. 3 The SUN proposal for dosage of sleep. Current evidence suggests that taking naps of $\sim 20 \mathrm{~min}$ decreases the sleep pressure. We propose the unit of 1 SUN for 20 min of napping as a dosage of sleep for managing excessive daytime sleepiness 
sleep trackers offering a useful support to monitor the sleep dosage [65-67]. Thus, using modern technology naps might be measured as proposed: The sleep dosage is defined in 1 Single Unit of Nap (1SUN) which is the equivalent of $20 \mathrm{~m}$ of napping (Fig. 3). This new perspective might be included in the personalized sleep medicine as part of the treatment for managing EDS. Despite that portable gadgets have demonstrated promising results for monitoring sleep, further research is needed to strengthen this proposed strategy.

\subsection{Future Perspectives Regarding the Sun Proposal}

Modern lifestyle requires high demand of waking time during nighttime. By invasion of sleeping time, the disruption of the circadian and homeostatic processes provokes several health issues such as obesity, psychiatric disorders, and sleep disturbances $[68,69]$. Among the highest prevalence of sleep complaints in population is EDS. The insufficient sleep has been associated with multiple negative health outcomes, such as an increase in mortality risk and negative labor efficiency including the reduction of productivity. For example, the USA sustains an annual economic loss higher than US\$280 billion linked to EDS [70, 71]. Here, we revised that naps could be considered as equivalent of a dosage for sleeping time as a medical intervention for EDS. This assumption is based in current data that have demonstrated that naps induce positive effects for releasing sleep pressure in EDS cases. However, the standardized uses of naps as a therapeutical approach require a precise methodology which should include the objective measurement for the sleep dosage. Following the idea of personalized medicine, with efficient examples in diets and exercise, naps might be prescribed under an objective dosage parameter. Moreover, by using a metric measurement of naps (1SUN), we propose that benefits of naps could promote a substantial life-quality improvement in patients with EDS. Hence, whenever naps are prescribed for patients, relevant guidelines regarding the metric measurement of napping must be strictly followed. Indeed, further clinical studies are required for testing the likely therapeutical properties of naps managing EDS in patients with different sleep disorders such as narcolepsy.

\section{Conclusions}

There are several medical approaches for managing EDS. However, a new therapeutical option might include the prescriptions of naps. We consider that this proposal will stimulate future studies to explore the possibility to consider the dosage of naps as part of the precise sleep medicine for managing EDS.

\section{Availability of data and material}

Authors reported published data from previous reports.

Author contributions EM-R, TY, DM, HB did literature search, data collection, data analysis, wrote the first draft of the manuscript. NBR, LC, DST, DT-C, ABV analyzed collected data. SM, CI, PT provided comments, and elaborated the figures. All authors approved the final version.

Funding This work was supported by the Escuela de Medicina, Universidad Anáhuac Mayab under Grant PresInvEMR2019 given to E. M-R.

\section{Compliance with Ethical Standards}

Conflict of interest The authors declare that they have no conflict of interest.

Code Availability Not applicable.

Ethics Approval Not applicable.

Consent to Participate This article does not contain any studies with human participants or animals performed by any of the authors.

Consent for Publication Not applicable.

\section{References}

1. Martin JS, Laberge L, Sasseville A, Bérubé M, Alain S, Houle J, Hébert M. Day and night shift schedules are associated with lower sleep quality in evening-types. Chronobiol Int. 2015;32:627-36. https://doi.org/10.3109/07420528.2015.10334 25.

2. Rod NH, Dissing AS, Clark A, Gerds TA, Lund R. Overnight smartphone use: a new public health challenge? A novel study design based on high-resolution smartphone data. PLoS ONE. 2018;13:e0204811. https://doi.org/10.1371/journal.pone.0204811.

3. Giuntella O, Mazzonna F. Sunset time and the economic effects of social jetlag: evidence from US time zone borders. J Health Econ. 2019;65:210-26. https://doi.org/10.1016/j.jhealeco.2019.03.007.

4. Hulsegge G, Loef B, van Kerkhof LW, Roenneberg T, van der Beek AJ, Proper KI. Shift work, sleep disturbances and social jetlag in healthcare workers. J Sleep Res. 2019;28:e12802. https ://doi.org/10.1111/jsr.12802.

5. Merdad RA, Akil H, Wali SO. Sleepiness in adolescents. Sleep Med Clin. 2017;12:415-28. https://doi.org/10.1016/j. jsmc.2017.03.014.

6. Kolla BP, He JP, Mansukhani MP, Kotagal S, Frye MA, Merikangas KR. Prevalence and correlates of hypersomnolence symptoms in US teens. J Am Acad Child Adolesc Psychiatry. 2019;58:71220. https://doi.org/10.1016/j.jaac.2018.09.435.

7. Chanchlani N. Health consequences of shift work and insufficient sleep. BMJ. 2017;356:i6599. https://doi.org/10.1136/sbmj.i6599.

8. Bogan RK. Getting serious about excessive sleepiness. Sleep Health. 2019;5:319. https://doi.org/10.1016/j.sleh.2019.07.005.

9. Hartse KM. The phylogeny of sleep. Handb Clin Neurol. 2011;98:97-109. https://doi.org/10.1016/B978-0-444-52006 $-7.00007-1$. 
10. Helfrich-Förster C. Sleep in insects. Ann Rev Entomol. 2018;63:69-866. https://doi.org/10.1146/annurev-ento-02011 7-043201.

11. Lesku JA, Ly LMT. Sleep origins: restful jellyfish are sleeping jellyfish. Curr Biol. 2017;27:R1060-R10621062. https://doi. org/10.1016/j.cub.2017.08.024.

12. Miyazaki S, Liu CY, Hayashi Y. Sleep in vertebrate and invertebrate animals, and insights into the function and evolution of sleep. Neurosci Res. 2017;118:3-12. https://doi.org/10.1016/j. neures.2017.04.017.

13. Anafi RC, Kayser MS, Raizen DM. Exploring phylogeny to find the function of sleep. Nat Rev Neurosci. 2019;20:109-16. https ://doi.org/10.1038/s41583-018-0098-9.

14. Khoury J, Doghramji K. Primary sleep disorders. Psychiatr Clin N Am. 2015;38:683-704. https://doi.org/10.1016/j.psc.2015.08.00.

15. Eban-Rothschild A, Appelbaum L, de Lecea L. Neuronal mechanisms for sleep/wake regulation and modulatory drive. Neuropsychopharmacology. 2018;43:937-52. https://doi.org/10.1038/ npp.2017.294.

16. Gent TC, Bassetti C, Adamantidis AR. Sleep-wake control and the thalamus. Curr Opin Neurobiol. 2018;52:188-97. https://doi. org/10.1016/j.conb.2018.08.002.

17. Holst SC, Landolt HP. Sleep-wake neurochemistry. Sleep Med Clin. 2018;13:137-46. https://doi.org/10.1016/j. jsmc.2018.03.002.

18. Iovino M, Messana T, De Pergola G, Iovino E, Guastamacchia E, Giagulli VA, Triggiani V. Vigilance states: central neural pathways, neurotransmitters and neurohormones. Endocr Metabol Immune Dis Drug Targets. 2019;19:26-37. https://doi. org/10.2174/1871530318666180816115720.

19. Borbély AA, Daan S, Wirz-Justice A, Deboer T. The twoprocess model of sleep regulation: a reappraisal. J Sleep Res. 2016;25:131-43. https://doi.org/10.1111/jsr.12371.

20. Persson PB, Bondke PA. Circadian rhythms. Acta Physiol. 2019;225:e13220. https://doi.org/10.1111/apha.13220.

21. Hajnik T, Tóth A, Szalontai Ö, Pethő M, Détári L. Sleep loss and recovery after administration of drugs related to different arousal systems in rats. Physiol Int. 2016;103:271-89. https:// doi.org/10.1556/2060.103.2016.3.9.

22. Dispersyn G, Sauvet F, Gomez-Merino D, Ciret S, Drogou C, Leger D, Gallopin T, Chennaoui M. The homeostatic and circadian sleep recovery responses after total sleep deprivation in mice. J Sleep Res. 2017;26:531-8. https://doi.org/10.1111/jsr.12541.

23. Skorucak J, Arbon EL, Dijk DJ, Achermann P. Response to chronic sleep restriction, extension, and subsequent total sleep deprivation in humans: adaptation or preserved sleep homeostasis? Sleep. 2018. https://doi.org/10.1093/sleep/zsy078.

24. Kim P, Oster H, Lehnert H, Schmid SM, Salamat N, Barclay JL, Maronde E, Inder W, Rawashdeh O. Coupling the circadian clock to homeostasis: the role of period in timing physiology. Endocr Rev. 2019;40:66-95. https://doi.org/10.1210/er.2018-00049.

25. Nair AB, Jacob S. A simple practice guide for dose conversion between animals and human. J Basic Clin Pharm. 2016;7:27-31. https://doi.org/10.4103/0976-0105.177703.

26. Leech RM, Timperio A, Livingstone KM, Worsley A, McNaughton SA. Temporal eating patterns: associations with nutrient intakes, diet quality, and measures of adiposity. Am J Clin Nutr. 2017;106:1121-30. https://doi.org/10.3945/ajcn.117.15658 8.

27. Locke A, Schneiderhan J, Zick SM. Diets for health: goals and guidelines. Am Fam Phys. 2018;97:721-8.

28. Rigal N, Champel C, Hébel P, Lahlou S. Food portion at ages 8-11 and obesogeny: the amount of food given to children varies with the mother's education and the child's appetite arousal. Soc Sci Med. 2019;228:111-6. https://doi.org/10.1016/j.socsc imed.2019.03.027.
29. Wright B, Bragge P. Interventions to promote healthy eating choices when dining out: a systematic review of reviews. Brit J Health Psychol. 2018;23:278-95. https://doi.org/10.1111/ bjhp. 12285 .

30. Budde H, Schwarz R, Velasques B, Ribeiro P, Holzweg M, Machado S, Brazaitis M, Staack F, Wegner M. The need for differentiating between exercise, physical activity, and training. Autoimmun Rev. 2016;15(1):110-1. https://doi.org/10.1016/j. autrev.2015.09.004

31. Leggi M, Bendini MG, D'Emidio S, Caldarone E, Lombardi M, Severi P, Stavri DC, Armeni M, Bravi V, Mazza A. Exercise dose in clinical practice: right is better than more. Cardiol J. 2018;25:287-8. https://doi.org/10.5603/CJ.2018.0040.

32. Gonzalo-Encabo P, McNeil J, Boyne DJ, Courneya KS, Friedenreich CM. Dose-response effects of exercise on bone mineral density and content in post-menopausal women. Scand J Med Sci Sports. 2019;29:1121-9. https://doi.org/10.1111/sms.13443.

33. Jones SA, Wen F, Herring AH, Evenson KR. Correlates of US adult physical activity and sedentary behavior patterns. J Sci Med Sport. 2016;19:1020-7. https://doi.org/10.1016/j.jsams .2016.03.009.

34. Santos-Lozano A, Pareja-Galeano H, Lucia A. Is weekend-only physical activity enough to compensate for a sedentary lifestyle? JAMA Int Med. 2017;177:1223-4. https://doi.org/10.1001/jamai nternmed.2017.2374.

35. Bourdier P, Saidi O, Rochette E, Ratel S, Merlin E, Pereira B, Duché P. Physical activity and sedentary levels in children with juvenile idiopathic arthritis and inflammatory bowel disease. A systematic review and meta-analysis. Pediatr Res. 2019;86:14956. https://doi.org/10.1038/s41390-019-0409-5.

36. Vainshelboim B, Brennan GM, LoRusso S, Fitzgerald P, Wisniewski KS. Sedentary behavior and physiological health determinants in male and female college students. Physiol Behav. 2019;204:277-82. https://doi.org/10.1016/j.physbeh.2019.02.041.

37. Yang L, Cao C, Kantor ED, Nguyen LH, Zheng X, Park Y, Giovannucci EL, Matthews CE, Colditz GA, Cao Y. Trends in sedentary behavior among the US population, 2001-2016. J Am Med Assoc. 2019;321:1587-97. https://doi.org/10.1001/ jama.2019.3636.

38. Brooks J, Ahmad I, Easton G. Promoting physical activity: the general practice agenda. Br J Gen Pract. 2016;66:454-5. https:// doi.org/10.3399/bjgp16X686689.

39. Wasfy MM, Baggish AL. Exercise dose in clinical practice. Circulation. 2016;133:2297-313. https://doi.org/10.1161/CIRCU LATIONAHA.116.018093.

40. Araújo CGS, Castro CLB, Franca JF, Silva CGSE. Aerobic exercise and the heart: discussing doses. Arq Bras Cardiol. 2017;108:271-5. https://doi.org/10.5935/abc.20170020.

41. Machado S, Filho ASS, Wilbert M, Barbieri G, Almeida V, Gurgel A, Rosa CV, Lins V, Paixão A, Santana K, Ramos G, Neto GM, Paes F, Rocha N, Murillo-Rodríguez E. Physical exercise as stabilizer for Alzheimer's disease cognitive decline: current status. Clin Pract Epidemiol Ment Health. 2017;13:181-4. https://doi. org/10.2174/1745017901713010181.

42. Gronwald T, Velasques B, Ribeiro P, Machado S, Murillo-Rodríguez E, Ludyga $S$, Yamamoto T, Budde H. Increasing exercise's effect on mental health: exercise intensity does matter. Proc Natl Acad Sci USA. 2018;115:E11890-E118911891. https://doi. org/10.1073/pnas.1818161115.

43. Monteiro D, Teixeira DS, Travassos B, Duarte-Mendes P, Moutão J, Machado S, Cid L. Perceived effort in football athletes: the role of achievement goal theory and self-determination theory. Front Psychol. 2018;9:1575. https://doi.org/10.3389/fpsyg.2018.01575.

44. Rodrigues F, Bento T, Cid L, Pereira Neiva H, Teixeira D, Moutão J, Almeida Marinho D, Monteiro D. Can interpersonal behavior influence the persistence and adherence to physical 
exercise practice in adults? A systematic review. Front Psychol. 2018;9:2141. https://doi.org/10.3389/fpsyg.2018.02141.

45. Gabriel BM, Zierath JR. Circadian rhythms and exercise-resetting the clock in metabolic disease. Nat Rev Endocrinol. 2019;15:197-206. https://doi.org/10.1038/s41574-018-0150-x.

46. Hieda M, Howden E, Shibata S, Fujimoto N, Bhella PS, Hastings JL, Tarumi T, Sarma S, Fu Q, Zhang R, Levine BD. Impact of lifelong exercise training dose on ventricular-arterial coupling. Circulation. 2018;138:2638-47.

47. Hower IM, Harper SA, Buford TW. Circadian rhythms, exercise, and cardiovascular health. J Circadian Rhythms. 2018;16:7. https ://doi.org/10.5334/jcr.164.

48. Duglan D, Lamia KA. Clocking in, working out: circadian regulation of exercise physiology. Trends Endocrinol Metabol. 2019;30:347-56. https://doi.org/10.1016/j.tem.2019.04.003.

49. Walch OJ, Cochran A, Forger DB. A global quantification of "normal" sleep schedules using smartphone data. Sci Adv. 2016;2:e1501705. https://doi.org/10.1126/sciadv.1501705.

50. MacDonald KJ, Lockhart HA, Storace AC, Emrich SM, Cote KA. A daytime nap enhances visual working memory performance and alters event-related delay activity. Cogn Affec Behav Neurosci. 2018;18:1105-20. https://doi.org/10.3758/s13415-018-0625-1.

51. McDevitt EA, Sattari N, Duggan KA, Cellini N, Whitehurst LN, Perera C, Reihanabad N, Granados S, Hernandez L, Mednick $\mathrm{SC}$. The impact of frequent napping and nap practice on sleepdependent memory in humans. Sci Rep. 2018;8:15053. https:// doi.org/10.1038/s41598-018-33209-0.

52. Petit E, Bourdin H, Tio G, Yenil O, Haffen E, Mougin F. Effects of a 20-min nap post normal and jet lag conditions on P300 components in athletes. Int J Sports Med. 2018;39:508-16. https://doi. org/10.1055/a-0599-0888.

53. Davy J, Göbel M. The effects of extended nap periods on cognitive, physiological and subjective responses under simulated night shift conditions. Chronobiol Int. 2018;35:169-87. https:// doi.org/10.1080/07420528.2017.1391277.

54. Fang SC, Huang CJ, Wu YL, Wu PY, Tsai PS. Effects of napping on cognitive function modulation in elderly adults with a morning chronotype: a nationwide survey. J Sleep Res. 2018. https://doi. org/10.1111/jsr.12724.

55. Guarnie Riribeiro Bueno C, Andrechuk CRS, Guimarães Lima M, Ceretta Oliveira H, Zancanell H, Berti de Azevedo Barros M, Marchiori de Oliveira TA, Ceolim MF. Napping, functional capacity and satisfaction with life in older adults: a population-based study. J Clin Nurs. 2019;28:1568-76. https://doi.org/10.1111/ jocn. 14768 .

56. Owusu JT, Wennberg AMV, Holingue CB, Tzuang M, Abeson $\mathrm{KD}$, Spira AP. Napping characteristics and cognitive performance in older adults. Int J Geriat Psychiatry. 2019;34:87-96. https://doi. org/10.1002/gps.4991.

57. König IR, Fuchs O, Hansen G, von Mutius E, Kopp MV. What is precision medicine? Eur Respir J. 2017;50:1700391. https://doi. org/10.1183/13993003.00391-2017.

58. Arnulf I, Leu-Semenescu S, Dodet P. Precision medicine for idiopathic hypersomnia. Sleep Med Clin. 2019;14:333-50. https:// doi.org/10.1016/j.jsmc.2019.05.007.

59. Martinez-Garcia MA, Campos-Rodriguez F, Barbé F, Gozal D, Agustí A. Precision medicine in obstructive sleep apnoea.
Lancet Respir Med. 2019;7:456-64. https://doi.org/10.1016/ S2213-2600(19)30044-X.

60. Pichard LE, Simonelli G, Schwartz L, Balkin TJ, Hursh S. Precision medicine for sleep loss and fatigue management. Sleep Med Clin. 2019;14:399-406. https://doi.org/10.1016/j. jsmc.2019.05.006.

61. Baiardi S, Mondini S. Inside the clinical evaluation of sleepiness: subjective and objective tools. Sleep Breath. 2019. https://doi. org/10.1007/s11325-019-01866-8.

62. Liu Y, Zhang J, Li SX, Chan NY, Yu MWM, Lam SP, Chan JWY, Li AM, Wing YK. Excessive daytime sleepiness among children and adolescents: prevalence, correlates, and pubertal effects. Sleep Med. 2019;53:1-8. https://doi.org/10.1016/j.sleep.2018.08.028.

63. Kosorok MR, Laber EB. Precision medicine. Ann Rev Stat Appl. 2019;6:263-86. https://doi.org/10.1146/annurev-statistics-03071 8-105251.

64. Ross R, Goodpaster BH, Koch LG, Sarzynski MA, Kohrt WM, Johannsen NM, Skinner JS, Castro A, Irving BA, Noland RC, Sparks LM, Spielmann G, Day AG, Pitsch W, Hopkins WG, Bouchard C. Precision exercise medicine: understanding exercise response variability. Br J Sports Med. 2019;53:1141-53. https:// doi.org/10.1136/bjsports-2018-100328.

65. de Zambotti M, Cellini N, Goldstone A, Colrain IM, Baker FC. Wearable sleep technology in clinical and research settings. Med Sci Sports Exerc. 2019;51:1538-57. https://doi.org/10.1249/ MSS.0000000000001947.

66. Gruwez A, Bruyneel AV, Bruyneel M. The validity of two commercially-available sleep trackers and actigraphy for assessment of sleep parameters in obstructive sleep apnea patients. PLoS ONE. 2019;14:e0210569. https://doi.org/10.1371/journal.pone.0210569.

67. Shin G, Jarrahi MH, Fei Y, Karami A, Gafinowitz N, Byun A, Lu X. Wearable activity trackers, accuracy, adoption, acceptance and health impact: a systematic literature review. J Biomed Inf. 2019;93:103153. https://doi.org/10.1016/j.jbi.2019.103153.

68. Hernández-García J, Navas-Carrillo D, Orenes-Piñero E. Alterations of circadian rhythms and their impact on obesity, metabolic syndrome and cardiovascular diseases. Crit Rev Food Sci Nutr. 2019. https://doi.org/10.1080/10408398.2018.1556579.

69. Martín-Olalla JM. Seasonal synchronization of sleep timing in industrial and pre-industrial societies. Sci Rep. 2019;9:6772. https ://doi.org/10.1038/s41598-019-43220-8.

70. Barnes CM, Watson NF. Why healthy sleep is good for business. Sleep Med Rev. 2019;47:112-8. https://doi.org/10.1016/j. smrv.2019.07.005.

71. Sunwoo JS, Shin DS, Hwangbo Y, Kim WJ, Chu MK, Yun CH, Jang T, Yang KI. High risk of obstructive sleep apnea, insomnia, and daytime sleepiness among commercial motor vehicle drivers. Sleep Breath. 2019;23:979-85. https://doi.org/10.1007/s1132 5-019-01805-7.

Publisher's Note Springer Nature remains neutral with regard to jurisdictional claims in published maps and institutional affiliations. 